\title{
El dolmen de Soto. Una construcción megalítica monumental de la Prehistoria Reciente de la Península Ibérica
}

José Antonio Linares Catela | arqueólogo. Cota Cero Gestión del Patrimonio Histórico SL Coronada Mora Molina | Becaria de Investigación del MINECO. Dpto. Prehistoria y Arqueología, Universidad de Sevilla

URL de la contribución <www.iaph.es/revistaph/index.php/revistaph/article/view/3669>

\section{RESUMEN}

El dolmen de Soto (Trigueros, Huelva) se define como una de las arquitecturas megalíticas monumentales en piedra y arcilla más singulares y excepcionales de la Península Ibérica. Es uno de los yacimientos arqueológicos referentes para el conocimiento del megalitismo, destacando su grandiosa arquitectura y sus excepcionales grafías en el contexto de la Prehistoria de Europa. Ha sido objeto de diversos estudios arqueológicos y restauraciones desde su descubrimiento y primera publicación en 1924, reconociéndose su valor patrimonial desde 1931, cuando fue declarado monumento nacional.

Las recientes actuaciones patrimoniales promovidas por la Consejería de Cultura de la Junta de Andalucía han contribuido a un mayor conocimiento científico del monumento megalítico y al establecimiento de determinadas directrices para su conservación y puesta en valor. El objetivo principal ha sido convertirlo en el sitio central del itinerario cultural conocido como la ruta dolménica de Huelva, dotando de contenidos a su centro de visitantes, desde el que se recepciona y aporta material divulgativo a los ciudadanos. Sin embargo, a pesar de los grandes esfuerzos realizados hasta el presente, no se ha conseguido una gestión integral del sitio, que aúne una investigación arqueológica continuada, una conservación preventiva del yacimiento, un mantenimiento periódico del monumento y una adecuada difusión, que garanticen su conocimiento, preservación y valoración social. Este es el gran reto para el futuro, que posicionaría a este monumento megalítico en el lugar que le corresponde, como uno de los bienes patrimoniales referentes de los paisajes culturales de la Prehistoria de Andalucía.

\section{Palabras clave}

Dolmen de Soto | Dólmenes | Huelva (provincia) | Megalitos | Prehistoria | Trigueros (Huelva) | 


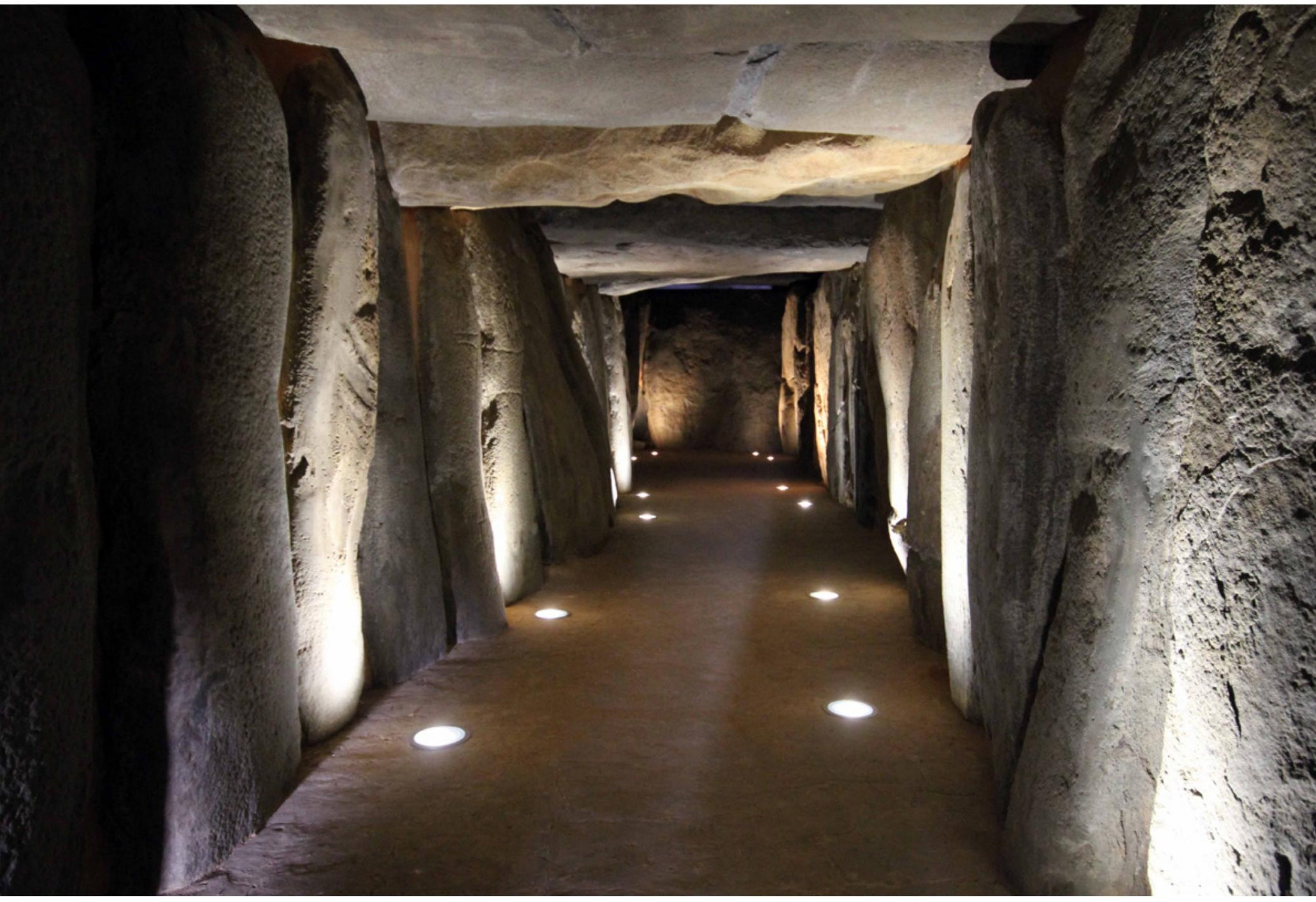

Galería megalítica tras su restauración. Vista desde la cabecera | foto José Antonio Linares Catela y Coronada Mora Molina, de todas las imágenes que ilustran este artículo, si no se indica lo contrario 
1

Atividad Arqueológica Puntual de Apoyo a la Restauración, $3^{a}$ fase (2012-2013), realizada por el equipo técnico de Cota Cero Gestión del Patrimonio Histórico S. L. y dirigida por el arqueólogo José Antonio Linares Catela.

2

Estudio realizado por el equipo especializado de la Universidad de Alcalá de Henares, compuesto por los catedráticos de Prehistoria Primitiva Bueno Ramírez y Rodrigo de Balbín Berhmann, y la profesora titular de Prehistoria Rosa Barroso Bermejo.

1. Descubrimiento y excavación del dolmen de Soto en 1923. Visita del Duque de Alba, Armando de Soto y Hugo Obermaier (de izquierda a derecha) | fuente AA.VV., 2014

2. Emplazamiento del dolmen de Soto. Excavaciones arqueológicas de 2012

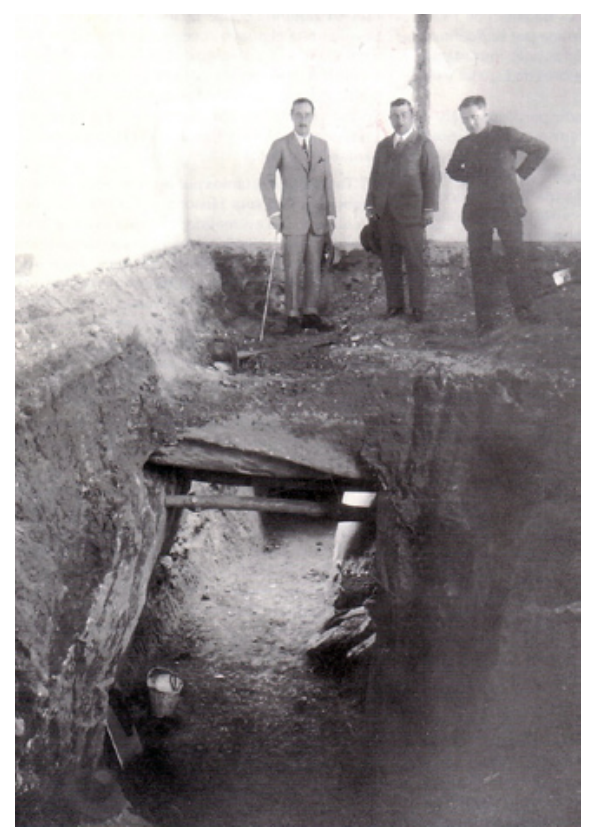

El dolmen de Soto fue descubierto y excavado por Armando de Soto en 1923 (imagen 1). En 1924 fue publicado por el prehistoriador Obermaier, que destacó su grandiosa arquitectura y la riqueza de los grabados en los ortostatos como un caso verdaderamente singular en el contexto del megalitismo europeo del momento (OBERMAIER, 1924). Desde entonces ha sido objeto de diversas investigaciones arqueológicas (BALBÍN BERHMANN; BUENO RAMÍREZ, 1996; BUENO RAMÍREZ; BALBÍN BERHMANN; BARROSO BERMEJO, 2015; PIÑÓN VARELA, 2004; RODRÍGUEZ BAYONA; NOCETE CALVO; DE FRANCO INÁCIO, et ál., 2010; SHEE TWOHIG, 1981), obras de restauración (GÓMEZ DE TERREROS GUARDIOLA, 2005) y estudios regionales (GARCÍA SANJUÁN; LINARES CATELA, 2009; LEISNER; LEISNER, 1943; LINARES CATELA, 2011), poniéndose de relieve su monumentalidad, su colosal tamaño y la gran abundancia y diversidad de las grafías representadas en la galería megalítica que demuestran su alto valor simbólico (BUENO RAMÍREZ; BALBÍN BERHMANN; BARROSO BERMEJO, 2015). Por tanto, el dolmen de Soto es uno de los monumentos megalíticos más relevantes de la Península Ibérica y un claro exponente de la primera arquitectura monumental en piedra de Europa occidental en la Prehistoria Reciente, contando con un enorme potencial patrimonial para ser considerado un referente arqueológico internacional del megalitismo (imagen 2).

La intervención arqueológica de apoyo a la conservación ${ }^{1}$ y el estudio de las grafías $^{2}$ (grabados y pinturas) realizadas en los años 2012-2013 en el marco del Proyecto de Conservación y Puesta en Valor, promovido por la Junta de Andalucía, ha supuesto un salto cualitativo y cuantitativo en el conocimiento

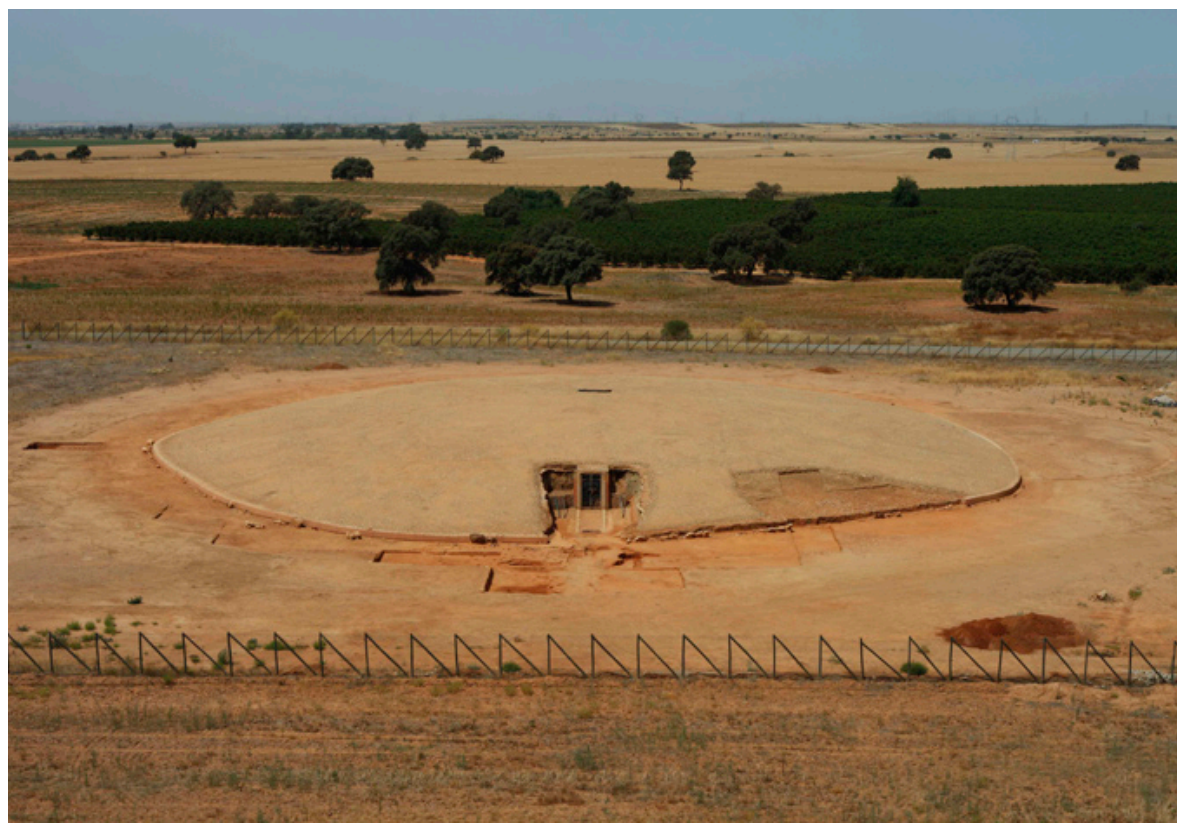


y conservación del monumento (AA. VV., 2014). La investigación arqueológica ha permitido obtener una abundante y rigurosa documentación de la arquitectura, de los discursos gráficos y de los espacios externos del monumento megalítico, además del establecimiento de criterios de conservación y restauración para este excepcional bien patrimonial (LINARES CATELA, 2013).

La metodología arqueológica desarrollada se ha centrado en dos aspectos interrelacionados. Por un lado, la excavación en extensión del área de la fachada de acceso al dolmen y de su espacio interno, realizándose una documentación y registro microespacial de las estructuras intervenidas y un levantamiento microtopográfico del monumento y su emplazamiento. Por otro, el estudio y documentación de los soportes decorados de la galería megalítica, llevándose a cabo calcos digitales, levantamiento fotogramétrico y análisis de los pigmentos mediante microscopía Raman y tubo de difracción de rayos $\mathrm{X}$ in situ de ortostatos y losas de cubierta.

Las excavaciones en los espacios externos y el atrio han posibilitado conocer la existencia de estructuras de cronología Neolítica previas al dolmen (imagen 3). Se ha constatado la presencia de fosas de cimentación y bloques de piedra que podrían corresponderse con un círculo de $60 \mathrm{~m}$ de diámetro compuesto por piedras de distintas materias primas y formas: bloques, menhires y estelas-menhires de grauvaca, calcarenitas y conglomerados ferruginosos de tamaños diversos, distribuidos equidistantemente. Al exterior de este círculo de piedras se ha registrado un conjunto de estructuras:

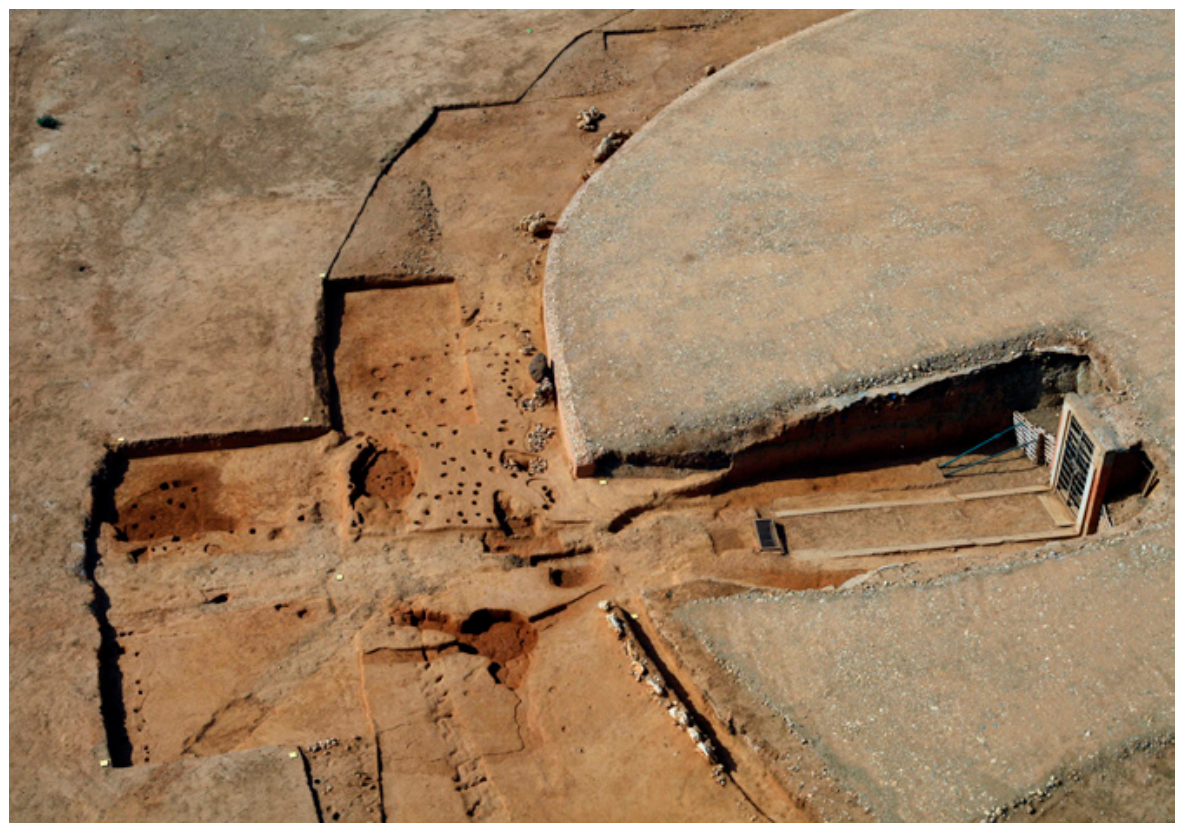

3. Conjunto de estructuras neolíticas localizadas en el área externa de acceso al dolmen 

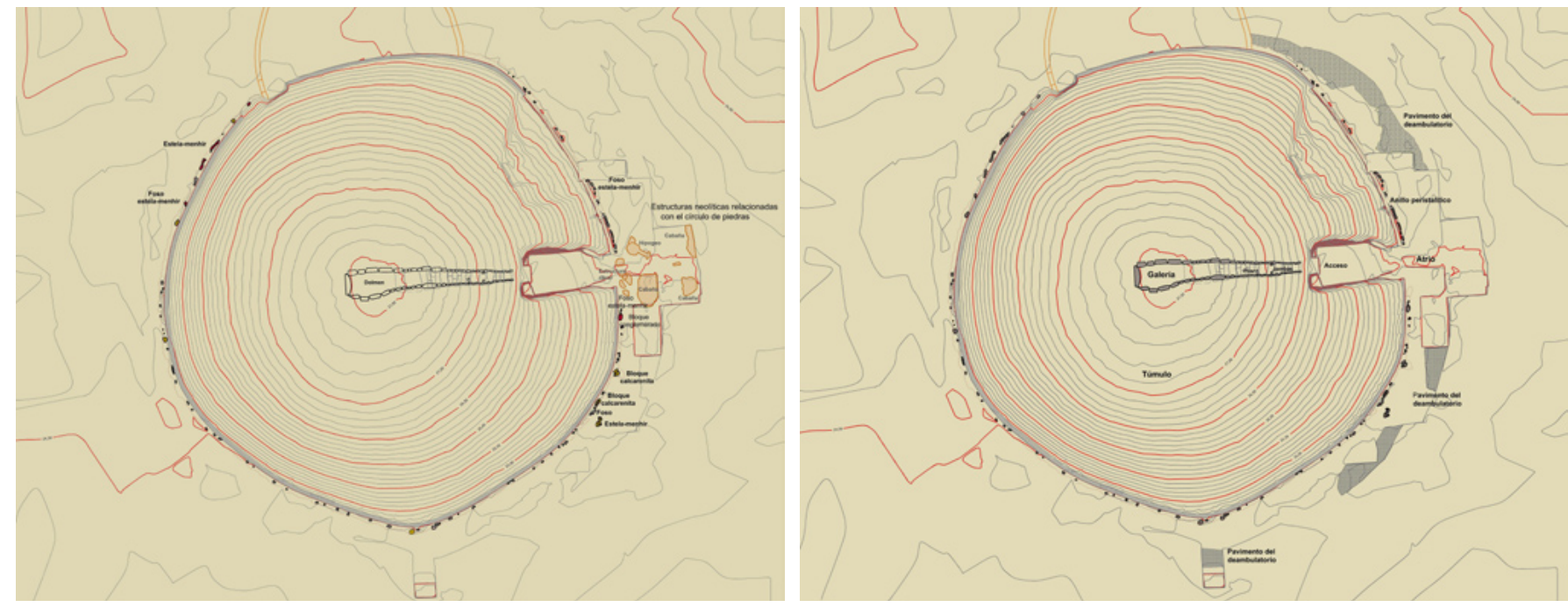

4. Planta de los elementos del círculo de piedras y estructuras neolíticas asociadas 5. Planta de los elementos arquitectónicos que conforman el dolmen
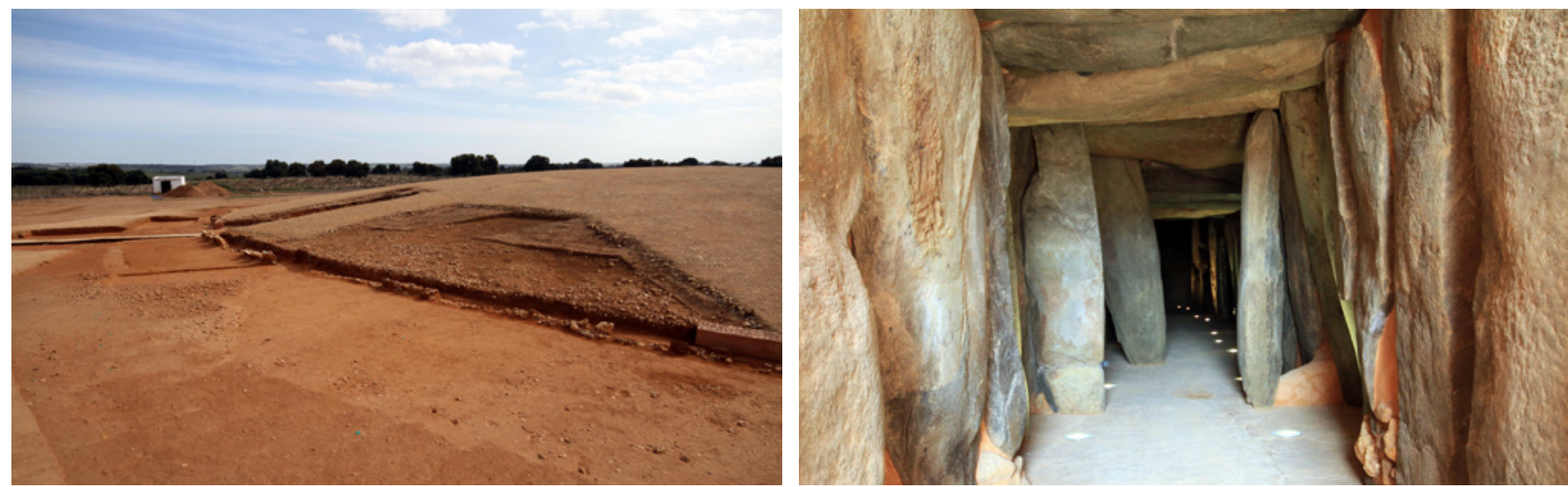

6. Detalle del sector noroeste del túmulo, anillo peristalítico y deambulatorio

7. Galería megalítica desde el acceso tras su restauración
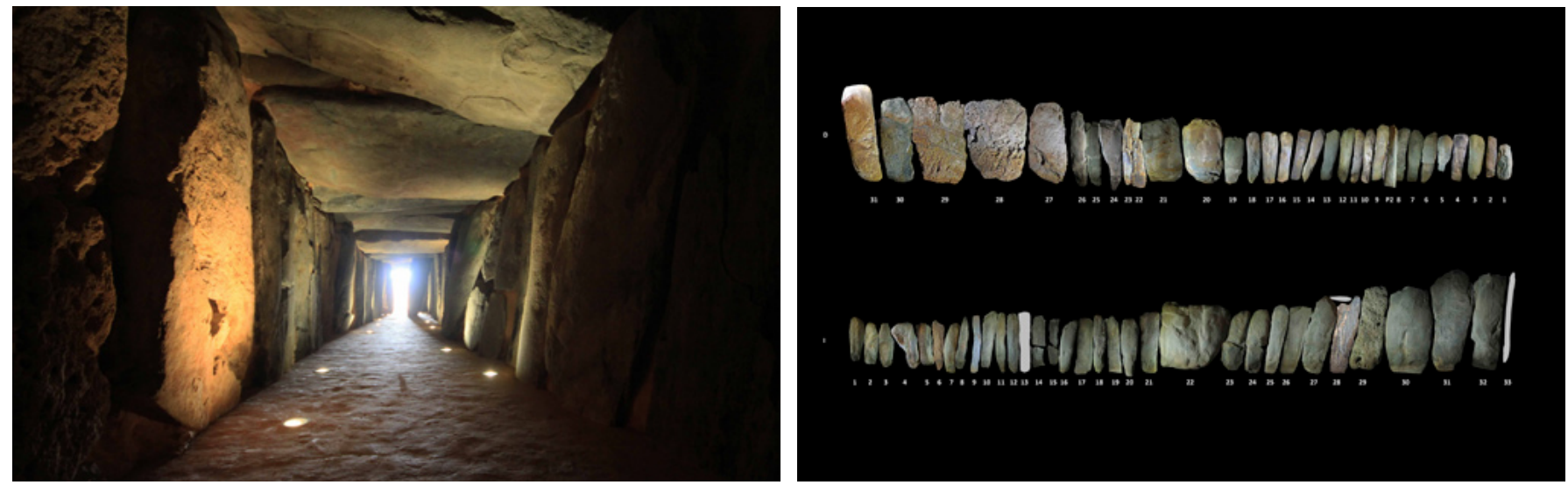

8. Vista de la gran cámara megalítica tras su restauración desde la cabecera

9. Alzados fotogramétricos de las paredes de la estructura megalítica | fuente AA.VV. 2014; BUENO RAMÍREZ; BALBÍN BERHMANN; BARROSO BERMEJO, 2015 
cabañas, hogueras, estructuras votivas o rituales e hipogeo, que se deben relacionar con el conjunto de las prácticas sociales llevadas a cabo en el lugar (imagen 4).

En una fase posterior se llevó a cabo la transformación arquitectónica y monumentalización del sitio. Se erigió la gran construcción funeraria: el dolmen, contenido dentro de un túmulo de 3,50 $\mathrm{m}$ de altura y de trazado similar al pretérito círculo de piedras (imagen 5). Fue construido mediante continuadas capas de arcilla, y rematado con un nivel de cantos de cuarzos y cuarcitas que lo hacían resaltar visualmente en el paisaje en un radio de varios kilómetros sobre la zona llana que lo circunda. Está delimitado por un anillo peristalítico de bloques de calcarenitas, conglomerados ferruginosos, lajas de pizarra y grauvacas dispuestos por grupos, al que se adosa un deambulatorio de $5 \mathrm{~m}$ de anchura, definido por un pavimento de cantos de cuarzo y cuarcita cuya función debió estar vinculada al tránsito del espacio externo (imagen 6).

La gran galería cubierta, orientada hacia el este, alcanza 21,50 m de longitud, presentando una anchura y altura que se incrementan de manera progresiva hasta la cabecera. Su acceso está precedido por un atrio intratumular abierto. En esta estructura ortostática se distinguen varios sectores: vestíbulo de acceso, antecámara, con presencia de dos jambas y un pilar (imagen 7), y la gran cámara, en donde se presentan los ortostatos de mayores dimensiones y peso (imagen 8). La pared derecha está compuesta por 30 ortostatos, la izquierda por 33, y la cabecera preside la estructura con una gran losa de 3,40 m de altura y 3,10 m de anchura, contándose con numerosas estelas y estelas-menhires reempleadas en la construcción. Se preservan 20 losas de cubierta, entre las cuales abundan menhires reutilizados. Su firme originario estaba formado por un pavimento de arcilla dispuesto en rampa descendente desde la entrada hasta la cabecera.

Mediante el estudio geoarqueológico se ha concluido que la mayoría de los ortostatos y de las losas de cubierta son de grauvaca, procediendo de diversos afloramientos al norte del monumento, en el cauce del arroyo Candón, en torno a $5 \mathrm{~km}$ de distancia. También se presentan otros materiales de medios geológicos más lejanos: calcarenitas del área de Niebla, areniscas, e incluso dos bloques de rocas volcánicas del Andévalo que afloran a más de $30 \mathrm{~km}$ de distancia.

La mayoría de los soportes de la galería megalítica están decorados (imagen 9), distinguiéndose dos tipos de tratamientos: grabados y pinturas, que en muchos casos se combinan en las mismas piezas. Los grabados se realizaron mediante distintas técnicas: incisión, piqueteado y abrasión, con una gran diversidad de motivos (imágenes 10, 11 y 12),entre los que destacan las armas representadas en las estelas antropomorfas. Las pinturas iden- 


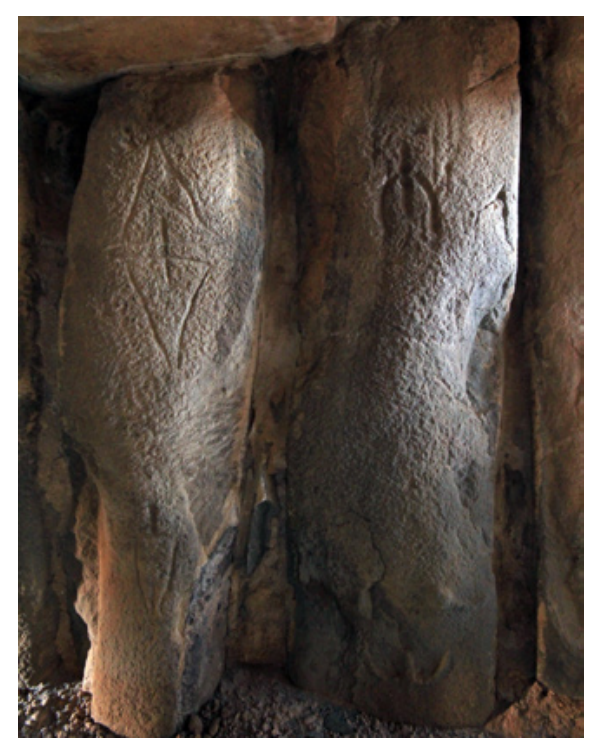

10. Ortostatos 20 (estela con grabados de armas) y 21 (estela antropomorfa) de la pared sur de la estructura megalítica

11. Detalle del grabado de la jamba derecha

12. Grabado antropomorfo del ortostato 26 de la pared norte | fotos José Antonio Linares Catela
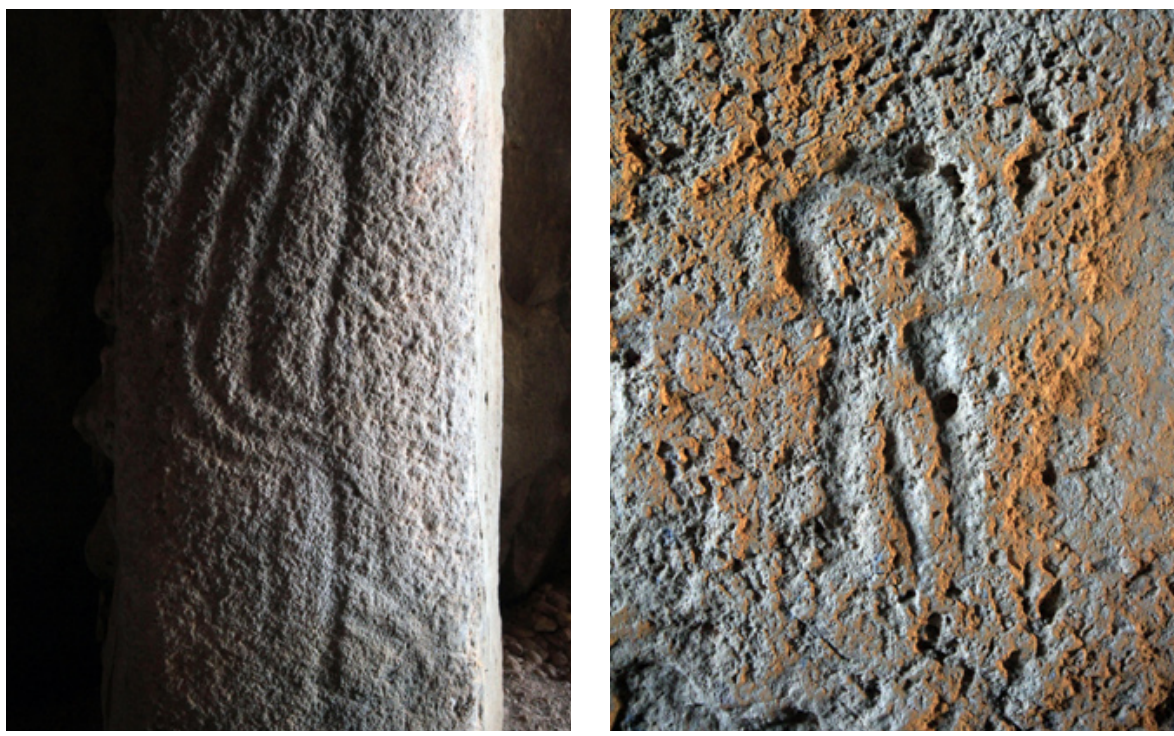

tificadas configuran una decoración policroma diversa, nunca antes documentada, compuestas por bases de imprimación blancas, pinturas rojas y negras. Por esto, el dolmen de Soto es uno de los monumentos megalíticos de mayor riqueza decorativa de Europa.

Además, los resultados de la investigación arqueológica han posibilitado establecer ciertas directrices para la conservación y restauración del monumento megalítico (imagen 13), como es el caso de las actuaciones de tapado y cubrición preventivas de las estructuras arqueológicas de los espacios externos, del anillo peristalítico, del túmulo y de la galería cubierta; la consolidación de las piezas que componen el anillo peristalítico; la restitución del pavimento de cantos de cuarzo y cuarcita del deambulatorio y del pavimento de arcilla interno del dolmen; además de criterios de limpieza y consolidación de los ortostatos y losas de cubierta; e iluminación de su interior. 


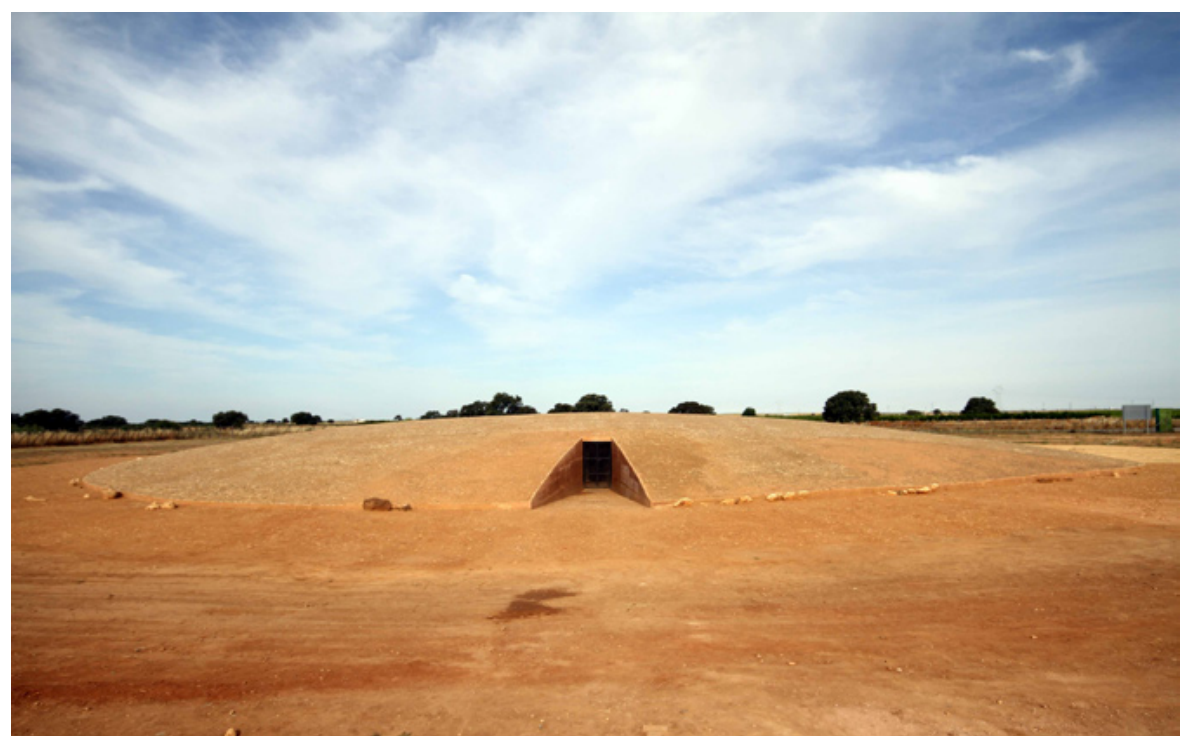

13. Dolmen de Soto tras su restauración. Vista del túmulo, deambulatorio y área de acceso

\section{BIBLIOGRAFÍA}

- AA. VV. (2014) Dolmen de Soto. Restauración y puesta en valor. Un proceso de diagnosis y conocimiento del bien cultural. Huelva: Consejería de Educación, Cultura y Deporte. Junta de Andalucía, 2014

- BALBín BERHMANN, R.; BUENO RAMíREZ, P. (1996) Soto, un ejemplo de arte megalítico al Suroeste de la Península Ibérica. En MOURE ROMANILLO, J. A. (ed.) “El hombre fósil" 80 años después. Santander: Universidad de Cantabria, Servicio de Publicaciones, 1996, pp. 467-503

- bueno RAMíREZ, P.; Balbín BERHMANN, R.; BARROSO BERMEJO, R. (2015) Graphic programmes as ideological constructions of megaliths: the south of the Iberian Peninsula as case of study. En ROCHA, L.; BUENO, P.; BRANCO, G. (ed.) Death As Archaeology of Transition: Thoughts and materials. BAR S2708. Oxford: Archaeopress, 2015, pp. 51-69

- GARCÍA SANJUÁN, L.; LINARES CATELA, J. A. (2009) Huelva. En GARCÍA SANJUÁN, L.; RUIZ GONZÁLEZ, B. (ed.) Las grandes piedras de la prehistoria, sitios y paisajes megalíticos de Andalucía. Sevilla: Consejería de CulturaJunta de Andalucía, 2009, pp. 143-185

- GÓMEZ DE TERREROS GUARDIOLA, M. T. (2005) Intervenciones en dólmenes 1953-1964. Proyectos de Félix Hernández Giménez: dólmenes de Matarrubilla y Cueva de la Pastora (Valencina de la Concepción, Sevilla), dolmen de Zancarrón de Soto (Trigueros, Huelva). Sevilla: Universidad de Sevilla, 2005

- LEISNER, G.; LEISNER, V. (1943) Die Megalithgräber der Iberischen Halbinsel. Der Suden. Berlín: Walter de Gruyter, 1943
- LINARES CATELA, J. A. (2011) Guía del megalitismo en la provincia de Huelva: territorios, paisajes y arquitecturas megalíticas. Sevilla: Consejería de Cultura, Junta de Andalucía, 2011

- LINARES CATELA, J. A. (2013) La puesta en valor de los monumentos megalíticos del Andévalo oriental (Huelva). Criterios arqueológicos de intervención y conservación. En HARO, J. DE; GARCÍA RINCÓN, J. M.; GÓMEZ TOSCANO, F. et ál. (coord.) Arqueología en la provincia de Huelva. Homenaje a Javier Rastrojo Lunar. Huelva: Universidad de Huelva, 2013, pp. 299-316

- OBERMAIER, H. (1924) El Dolmen de Soto (Trigueros, Huelva). Boletín de la Sociedad Española de Excursiones, año XXXII, 1924, pp. 1-31. Reproducción facsímil en Clásicos de la Arqueología de Huelva 4/1991. Huelva: Diputación de Huelva

- PIÑón VARELA, F. (2004) El horizonte cultural megalítico en el área de Huelva. Sevilla: Consejería de Cultura-Junta de Andalucía, 2004

- RODRÍGUez BAYONA, M.; NOCETE CALVO, F.; DE FRANCO INÁCIO, N. F. et ál. (2010) Excavación arqueológica puntual para el apoyo a la restauración y puesta en valor del dolmen de Soto (Trigueros, Huelva). Campaña de 2006. Anuario Arqueológico de Andalucía/2006, 2010, pp. 2231-2242

- SHEE TWOHIG, E. (1981) The megalithic art of western Europe. Oxford: Oxford University Press, 1981 